\title{
Релаксационные, термические и межфазные эффекты в композитах полимер-сегнетопьезокерамика различной структуры
}

\author{
(C) М.А. Курбанов ${ }^{1}$, И.С. Рамазанова ${ }^{1}$, З.А. Дадашов ${ }^{1}$, Ф.И. Мамедов ${ }^{3}$, Г.Х. Гусейнова ${ }^{1}$, \\ У.В. Юсифова ${ }^{1}$, Ф.Н. Татардар ${ }^{1,2}$, И.А. Фараджзаде 4 \\ ${ }^{1}$ Институт фризики Национальной академии наук Азербайджана, \\ Az-1143 Баку, Азербайджан \\ ${ }^{2}$ Университет Хазар, \\ Az-1096 Баку, Азербайджан \\ ${ }^{3}$ Академия при Министерстве чрезвычайных ситуаций, \\ Az-1089 Баку, Азербайджан \\ ${ }^{4}$ Институт радиационных проблем Национальной академии наук Азербайджана, \\ Az-1143 Баку, Азербайджан \\ E-mail: mKurbanov@physics.ab.az
}

Поступила в Редакцию 8 августа 2018 г.

В окончательной редакции 14 марта 2019 г.

Принята к публикации 26 марта 2019 г.

\begin{abstract}
Изучены релаксационные, термические процессы и межфазные явления в композитах на основе сегнетоэлектриков и полимерной матрицы. Показано, что величина заряда, стабилизированного на границе раздела фаз композита при его электротермополяризации, в основном определяется структурой полимерной матрицы и пьезоэлектрической фазы. Полученные результаты позволили выявить основные причины, влияющие на пьезоэлектрические свойства гетерогенной системы полимер-сегнетокерамика. В качестве органической фазы использовались полиолефины и фторсодержащие полярные полимеры, а в качестве неорганической фазы - сегнетокерамики ромбоэдрической, тетрагональной и смешанной структур. Релаксационные процессы и межфазные явления изучены применением дифференциально сканирующего калориметра, а зарядовое состояние - методом регистрации термостимулированного деполяризационного тока. Стабильность зарядового состояния определялась электретной разностью потенциалов композитов. Изучение молекулярной релаксации осуществлялось диэлектрическим методом. Установлено, что композиты, в которых межфазное взаимодействие проявляет себя сильнее имеют высокие пьезоэлектрические свойства.
\end{abstract}

Ключевые слова: сегнетоэлектрики, полимерная матрица, эндотермический эффект.

DOI: $10.21883 / F T P .2019 .08 .48004 .8970$

\section{1. Введение}

В настоящее время интенсивно растет объем исследований и расширяются области эксплуатации активных композитных материалов, в частности, пьезо-, пироэлектриков и электретов на основе полимерной матрицы и сегнетопьезокерамической частицы [1-6]. Поэтому важно изучить термические и релаксационные свойства указанных композитов, позволяющие раскрыть природу процессов, происходящих в пьезочастицах и диспергированных полимерах под действием сильного электрического поля и температуры [6-8]. Выявление связи между релаксационными, термическими и электротермическими свойствами также является весьма важной задачей в области композитного материаловедения [9-11]. Установление такой взаимосвязи позволит не только глубже понять механизм формирования пьезо-, пироэлектрических и электретных эффектов в композитах полимер-сегнетопьезокерамика, но и решить ряд задач, связанных с их практическим применением, в частности разработать материалы для композитных акустоэлектрических и электроакустических преобразователей различных назначений $[12,13]$.
Изучение релаксационных, термических и электротермических свойств полимеров и гетерогенных систем на их основе указывает на существование взаимосвязи между ними. Имеются основания предполагать, что такие свойства полимеров и полимерных композитов, как электроотрицательность (полярность) макромолекул полимерной матрицы и катионов сегнетопьезоэлектрической фазы, размеры и подвижность доменов, непосредственно участвуют в формировании различных релаксационных, межфазных эффектов и пьезоэлектрических свойств композитов $[14,15]$. Отметим, что имеющаяся информация о релаксационных, термических и межфазных явлениях в композитах позволяет оптимизировать режимы электротермополяризации композитов. В этой связи основным элементом научной новизны является выявление эффектов, определяющих величину макроскопических параметров композитных пьезо- и пироэлектриков.

Граничные поляризационные процессы определяют пьезоэлектрические свойства композитов полимерсегнетопьезокерамика. Следует подчеркнуть, что структура полимерной фазы, которая непосредственно контактирует с поверхностью пьезочастицы, существенно зависит от межфазных явлений. Именно межфазные и релаксационные явления будут в конечном итоге 
определять надмолекулярную структуру (НМС) полимерной фазы. Весьма важным фактором в формировании стабильной остаточной поляризации композитов являются релаксационные процессы, которые определяются в свою очередь температурой Кюри пьезоэлектрической фазы и температурой плавления полимерной матрицы. HМC полимерной фазы влияет на вероятность накопления зарядов на границе раздела фаз в процессе электротермополяризации. Вероятность накопления зарядов на границе раздела фаз зависит от подвижности доменных стенок, сегнетожесткости и размеров доменов пьезофазы. Поэтому изучение межфазных явлений, релаксационных и термических процессов в композитах позволит выявить основные факторы, определяющие пьезоэлектрические свойства композитов.

Цель работы заключается в изучении релаксационных, термических и межфазных эффектов в композитах на основе сегнетоэлектриков (диспергатор) и полимеров (матрица) различных структур.

\section{2. Методика эксперимента}

Процесс создания пьезоэлектрических композитов включает по меньшей мере четыре этапа: подготовка и выбор исходных компонентов, смешивание компонентов, получение из смеси композитного материала, поляризация композита. Выбор компонентов пьезоэлектрических композитов и метода получения композиционного материала диктуется комплексом свойств, которыми должен обладать конечный материал. К полимерным матрицам предъявляются определенные требования: легкая перерабатываемость, высокая пластичность и механическая прочность, повышенная диэлектрическая проницаемость и электрическая прочность, небольшие внутренние напряжения и релаксации структуры после прессования и поляризации. Анализ теплофизических, электрических и физико-механических свойств полимеров показал, что вышеуказанным требованиям в наибольшей степени отвечают термопластические фторуглеродистые полимеры и полимеры полиолефинового ряда. Следует отметить, что выбор матриц зависит от области применения активных полимерных композитов $[10,16]$. Например, при создании пьезокомпозита значение диэлектрической проницаемости $(\varepsilon)$ полимера должно быть высоким, а его объемная проводимость $\rho_{V}$ соизмерима с объемной проводимостью сегнетоэлектрика. Кроме того, производство термопластических полимеров уже хорошо освоено отечественной промышленностью, что является определяющим фактором с экономической точки зрения при разработке композиционных материалов и преобразователей различных назначений. Отметим, что используемые нами полимеры отличаются друг от друга своими физико-механическими, электрическими, теплофизическими, диэлектрическими свойствами и структурой.

В качестве активных наполнителей использованы наиболее эффективные сегнетопьезоэлектрики с различными кристаллофизическими и кристаллохимическими параметрами (пьезокерамика типа ПКР) на основе семейства цирконата-титаната свинца [14].

Исходные полимерные и пьезоэлектрические порошки тщательно смешивали на шаровой мельнице, а затем из смешанных порошков путем горячего прессования получены образцы композитов с необходимыми геометрическими размерами и формами. Метод горячего прессования является более эффективным для формирования беспористых и высоконаполненных композитов. Процесс горячего прессования характеризуется тремя основными технологическими параметрами - давлением, температурой и временем выдержки в расплавленном состоянии. Варьируя эти параметры, получим образцы с различными физико-механическими и пьезоэлектрическими свойствами. При выборе температуры прессования исходим из температуры плавления полимерной матрицы, ее текучести и литьевой усадки. Образцы выдерживаются в течение 3-5мин. при температуре плавления $T_{m}$ полимера под небольшим давлением, а затем при этой же температуре давление медленно поднимается до $15 \mathrm{MПа} \mathrm{и} \mathrm{в} \mathrm{этом} \mathrm{состоянии} \mathrm{образец}$ выдерживается в течение 10-15 мин. Далее снимается давление и композит быстро охлаждается в воде или он медленно охлаждается без снятия давления.

Заключительным этапом процесса изготовления образцов является их электротермополяризация. Сначала композит нагревают до температуры поляризации $T_{P}$, затем прикладывают постоянное электрическое поле поляризации $E_{P}$ и выдерживают в течение времени $t_{P}$ в поле, после чего, не снимая поле, охлаждают до комнатной температуры.

Этот метод поляризации позволяет в широком пределе варьировать величину энергии залегания и концентрации инжектированных зарядов в композите, что необходимо для решения поставленных задач в данной работе. Оптимальные условия поляризации, т.е. величины $E_{P}, T_{P}$ и $t_{P}$, определялись экспериментально по максимальному значению пьезоэлектрических коэффициентов отдельных композитов [5].

Измерения диэлектрической проницаемости $(\varepsilon)$ и тангенса угла диэлектрических потерь $(\operatorname{tg} \delta)$ проводились с помощью автоматического моста E8-4 на частоте 1 КГц в интервале температур $293-473$ К, электропроводность $\rho_{v}^{-1}$ - по остаточному току, который устанавливался спустя 0.5-2 часа после подачи напряжения $100 \mathrm{~B}$ на композит. Измерения образцов проводились с помощью тераомметра E6-13 А в интервале температур 293-473 К при линейном нагреве со скоростью 3 град/мин.

Теплофизические параметры определялись дифференциально сканирующим калориметром DSC 204 F1 Phoеnix, а зарядовое состояние - методом регистрации спектра термостимулированного деполяризационного тока. Методом ИК-спектроскопии оценивалось развитие окислительно-деструктивных явлений в полимерах при их диспергировании сегнеточастицами. Исследование проводилось на ИК-спектрофотометре Spekord 71 JR 
(с максимальным разрешением до $1 \mathrm{~cm}^{-1}$ ) при комнатной температуре в диапазоне $650-4000 \mathrm{~cm}^{-1}$.

\section{3. Экспериментальные результаты и обсуждение}

Ранее было отмечено, что электро- и теплофизические свойства композитов полимер-сегнетопьезокерамика являются показателем эффективности разработанных пьезо-, пироэлектрических материалов. Кроме этого, вариация вышеназванных эффектов позволяет целенаправленно изменять межфазные явления, релаксационные и термические процессы в исследуемых композитах. На рис. 1 приведена температурная зависимость плотности композитов на основе полипропилена (ПП) и пьезокерамик различных структур (ромбоэдрической $\left(R_{e}\right)$, тетроэдрической $(T)$ и смешанной $\left.\left(R_{e}+T\right)\right)$. Температурная зависимость плотности $(\rho)$ композита имеет три участка. На первом и третьем участках плотность композита линейно уменьшается с температурой, а на втором уменьшается скачкообразно. Первый участок зависимости $\rho$ от $T$ обусловлен тепловым расширением композита. При достижении температуры плавления кристаллической фазы полимера, из-за перехода от кристаллической фазы к аморфной, объем образца в узком температурном интервале резко возрастает, что приводит к скачкообразному уменьшению плотности. Третий участок зависимости $\rho(T)$ соответствует тепловому расширению аморфной фазы. Очевидно, что параметры, характеризующие температурную зависимость плотности композита, а именно коэффициенты теплового расширения на первом и третьем участках $\beta_{1}$ и $\beta_{2}$, скачок плотности $\Delta \rho$ и температурный интервал этого скачка $\Delta T_{\rho}$ на втором участке, отражают степень взаимодействия полимерной матрицы с наполнителем, так как это взаимодействие определяет степень упорядоченности полимерной матрицы и содержание кристаллической фазы в ней и, следовательно, интенсивность релаксационных процессов $[5,12,17-20]$. Чем больше будет степень взаимодействия полимера с наполнителем, тем меньше будет содержание кристаллической фазы. В табл. 1 приведены значения $\Delta \rho, \beta_{1}$ и $\Delta T_{\rho}$ для различных композитов (содержание наполнителя 50 об\%).

Из табл. 1 видно, что $\Delta \rho$ и $\beta_{1}$ меньше, а $\Delta T_{\rho}$ больше у композитов с наполнителем ромбоэдрической структуры, что свидетельствует о высокой степени взаимодействия полимера с наполнителем в этих композитах.

Таблица 1. Характеристики исследуемых композитов: $\Delta \rho$, $\Delta T_{p}, \beta_{1}$

\begin{tabular}{l|c|c|c|c}
\hline \multicolumn{1}{c|}{ Композит } & $\begin{array}{c}\Delta \rho, \\
\Gamma / \mathrm{cm}^{3}\end{array}$ & $\begin{array}{c}\Delta T_{p}, \\
\mathrm{~K}\end{array}$ & $\begin{array}{c}\beta_{1}, 10^{-4} \\
\mathrm{~K}^{-1}\end{array}$ & $\begin{array}{c}\text { Структура } \\
\text { наполнителя }\end{array}$ \\
\hline ПЭВП + ПКР-7 & 0.17 & 7 & 0.0910 & $T$ \\
ПЭВП + ПКР-51 & 0.19 & 5 & 0.0968 & $P+T$ \\
ПЭВП + ПКР-3 & 0.15 & 10 & 0.08757 & $P$
\end{tabular}

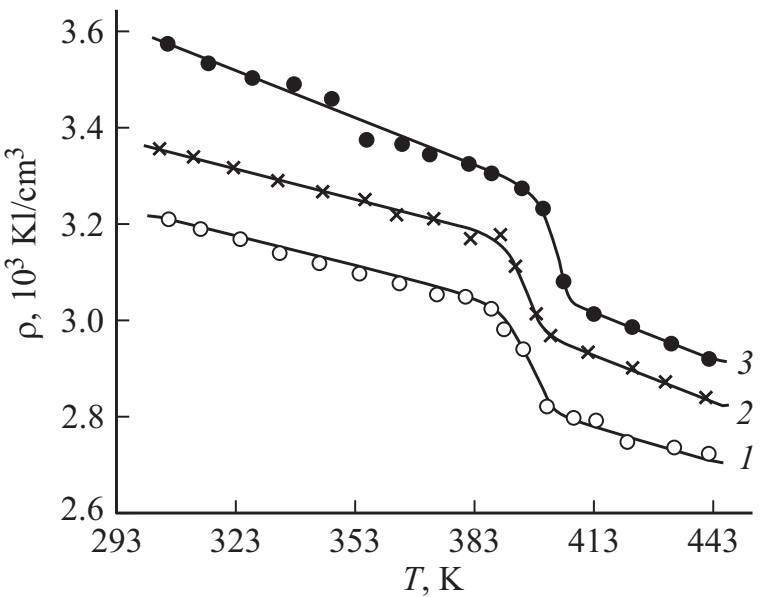

Рис. 1. Зависимость плотности $(\rho)$ от $T$ для композита: $1-$ ПП + ПКР-3; $2-\Pi \Pi+$ ПКР-3; $3-\Pi \Pi+$ ПКР-7.

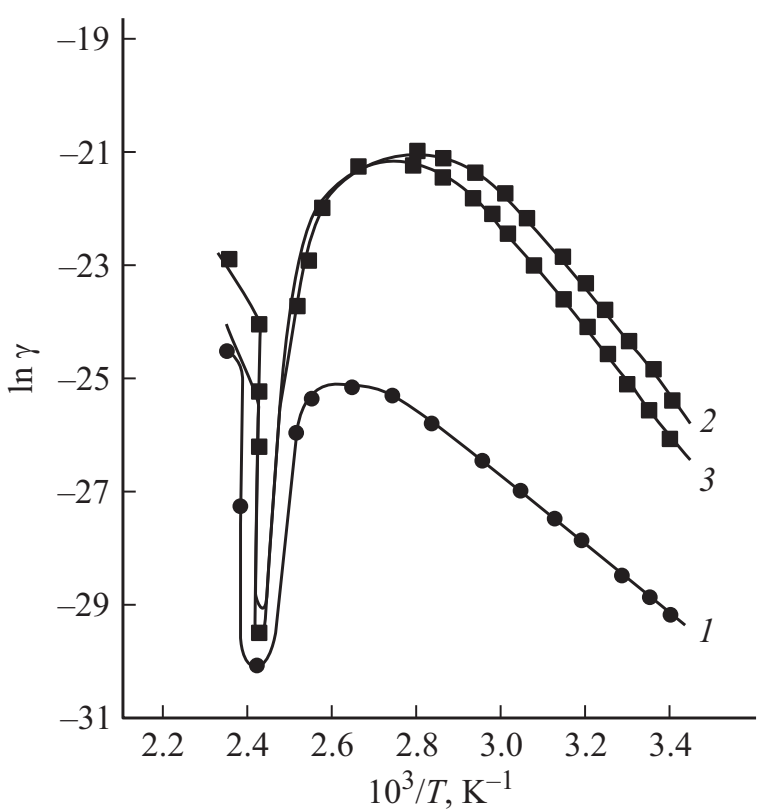

Рис. 2. Зависимость электропроводности $\gamma_{V}$ от $1 / T$ для композитов: $1-$ ПЭВП + ПКР-3; $2-$ ПЭВП + ПКР-7; $3-$ ПЭВП + ПКР-57.

Учитывая, что микроскопические параметры $\beta_{1}$ и $\beta_{2}$ непосредственно определяют подвижность молекулярных цепей полимерной матрицы композита, регистрируя температурные зависимости электропроводности, можем получить информацию о релаксационных, термических процессах и межфазных явлениях в композитах. Температурная зависимость электропроводности $\gamma_{V}$ композитов также имеет несколько, участков (рис. 2): на первом участке $\gamma_{V}$ с ростом температуры увеличивается, на втором участке вблизи температуры плавления кристаллической фазы полимера $\gamma_{V}$ резко уменьшается и, наконец, на третьем участке $\gamma_{V}$ снова возрастает. Переход от первого участка ко второму происходит плавно, при этом температурный интервал перехода 
существенно зависит от структуры наполнителя и условий кристаллизации полимерной матрицы композита. Указанные участки зависимости $\gamma_{V}(T)$ характеризуются наклоном температурного интервала, крутизной спада и роста. Все эти параметры зависят от степени взаимодействия между полимером и частицами наполнителя. Рассмотрим каждый из участков зависимости $\gamma_{V}(T)$ в отдельности. На первом участке с увеличением температуры $\ln \gamma_{V}$ композита практически линейно увеличивается, что связано с увеличением проводимости пьезочастиц по экспоненциальному закону, так как в этом температурном интервале изменение электропроводности полимера незначительно. Некоторый вклад в общую электропроводность композита в этой области вносит и тепловое расширение компонентов, в основном, полимерной матрицы. Это расширение увеличивает среднее расстояние между частицами пьезокерамики и, следовательно, высоты потенциального барьера между ними, что должно привести к уменьшению электропроводности композита. Высота барьера связана с шириной обедненного слоя $(d)$ уравнением Пуассона

$$
\varphi=\frac{e^{2} N_{s}}{2 \varepsilon_{k} \varepsilon_{0}} d^{2},
$$

где $e-$ заряд электрона, $\varepsilon_{0}-$ диэлектрическая постоянная, $\varepsilon_{k}$ - диэлектрическая проницаемость композита, $N_{s}$-- плотность заполненных локальных граничных состояний [7,21].

Так как соотношение вкладов электропроводности компонентов и теплового расширения зависит от температуры, это приводит к формированию переходного участка на температурной зависимости $\gamma_{V}$. Постепенное увеличение потенциального барьера между частицами способствует тому, что при определенной температуре рост электропроводности композита переходит к ее уменьшению. Вблизи температуры плавления кристаллической фазы полимера, из-за резкого увеличения объема полимерной матрицы, среднее расстояние и, следовательно, потенциальный барьер между частицами резко увеличиваются, и на зависимости $\gamma_{V}(T)$ наблюдается резкое уменьшение электропроводности, возникает позисторный эффект [5,21]. Необходимо отметить, что полученные нами зависимости $\rho(T)$ и $\gamma(T)$ позволяют определить оптимальные значения температуры поляризации, напряженности электрического поля поляризации $E_{p}$ и электрической прочности пьезо-, пиро- и электретных композитов.

В табл. 2 и 3 приведены значения энергии активации $E_{a}$ первого участка зависимости $\gamma_{V}(T)$, температурного интервала переходной области $\Delta T$, температуры максимума электропроводности $T_{M}$, крутизны $S$ третьего участка зависимости $\gamma_{V}(T)$, полуширины позисторного пика $\Delta T_{p}$ для композитов ПЭВП с наполнителем различной структуры. Указанные параметры непосредственно определяются релаксационными, термическими процессами и межфазными явлениями в композитах, диспергированных сегнетопьезоэлектрическими частицами различной структуры.
Таблица 2. Характеристики исследуемых композитов: $E_{a}, \Delta T$, $T_{M}, S, \Delta T_{p}$

\begin{tabular}{c|l|c|c|c|c|r}
\hline $\begin{array}{c}\text { Структура } \\
\text { наполнителя }\end{array}$ & \multicolumn{1}{|c|}{ Композит } & $\begin{array}{c}E_{a}, \\
\text { эВ }\end{array}$ & $\begin{array}{c}\Delta T, \\
\mathrm{~K}\end{array}$ & $\begin{array}{c}T_{M}, \\
\mathrm{~K}\end{array}$ & $\begin{array}{c}S, \\
\mathrm{~K}^{-1}\end{array}$ & $\begin{array}{c}\Delta T_{p}, \\
\mathrm{~K}\end{array}$ \\
\hline$P_{e}$ & ПЭВП+ ПКР-3 & 0.33 & 40.91 & 386.4 & 0.517 & 14.51 \\
$T$ & ПЭВП + ПКР-7 & 0.75 & 58.11 & 367.1 & 1.234 & 9.26 \\
$R_{e}+T$ & ПЭВП + ПКР-57 & 0.81 & 48.56 & 370.4 & 1.234 & 10.32
\end{tabular}

Таблица 3. Характеристики исследуемых композитов: $E_{a}, \Delta T$, $T_{M}, S, \Delta T_{p}$

\begin{tabular}{c|c|c|c|c|c|c}
\hline Композит & $\begin{array}{c}\text { Объемное } \\
\text { содержание, } \%\end{array}$ & $\begin{array}{c}E_{a}, \\
\text { эB }\end{array}$ & $\begin{array}{c}\Delta T, \\
\mathrm{~K}\end{array}$ & $\begin{array}{c}T_{M}, \\
\mathrm{~K}\end{array}$ & $\begin{array}{c}S, \\
\mathrm{~K}^{-1}\end{array}$ & $\begin{array}{c}\Delta T_{p}, \\
\mathrm{~K}\end{array}$ \\
\hline ПЭВП+ ПКР-7 & 30 & 0.75 & 58.11 & 367.1 & 1.234 & 9.26 \\
& 40 & 0.736 & 49.71 & 375.9 & 0.538 & 14.51 \\
& 50 & 0.536 & 21.79 & 392.2 & 0.552 & 18.48
\end{tabular}

Таблица 4. Характеристики исследуемых композитов: $\Delta \rho, E_{a}$, $\Delta T_{p}, d_{33}$

\begin{tabular}{|c|c|c|c|}
\hline Параметры & ПЭВП + ПКР-3 & ПЭВП + ПКР-7 & ПЭВП + ПКР-1 \\
\hline$\Delta \rho, \Gamma / \mathrm{cm}^{3}$ & 0.07 & 0.13 & 0.11 \\
\hline$E_{a},{ }, \mathrm{~B}$ & 0.33 & 0.75 & 0.71 \\
\hline$\Delta T_{p}, \mathrm{~K}$ & 14.51 & 9.26 & 10.32 \\
\hline$d_{33}$, пКл/Н & 76 & 33 & 42 \\
\hline
\end{tabular}

Видно, что в композитах с пьезонаполнителем ромбоэдрической структуры $E_{a}, \Delta T$ и $S$ меньше, а $T_{M}$ и $T_{p}$ больше по сравнению с композитами, содержащими наполнители тетрагональной или смешанной структур. Такие различия также позволяют предположить, что в композитах с частицами ромбоэдрической структуры степень взаимодействия между полимером и наполнителем больше. Подтверждением этого является уменьшение величины $\Delta E, \Delta T$ и $S$ и увеличение $T_{M}$ и $\Delta T_{p}$ после поляризации, что свидетельствует об увеличении степени взаимодействия между полимером и наполнителем.

Это возможно, если предложить, что в процессе поляризации изменяются поверхностные состояния пьезочастиц, они приобретают дипольный момент, а полимерные цепи в результате окислительно-деструктивных процессов приобретают полярность. После электротермополяризации композитов уменьшаются также $\Delta \rho$ и $\beta_{1}$, $\Delta T_{\rho}$ увеличивается, что подтверждают результаты, полученные из зависимости $\gamma_{V}(T)$.

Сопоставление пьезоэлектрических свойств композитов с параметрами, полученными из зависимостей $\gamma_{V}(T)$ и $\rho(T)$, показывает, что композиты, в которых степень взаимодействия наполнителя с полимером больше, имеют и большой пьезокоэффициент, что видно из табл. 4. 
Таблица 5. Теплофизические характеристики исследуемых полимеров и композитов на их основе

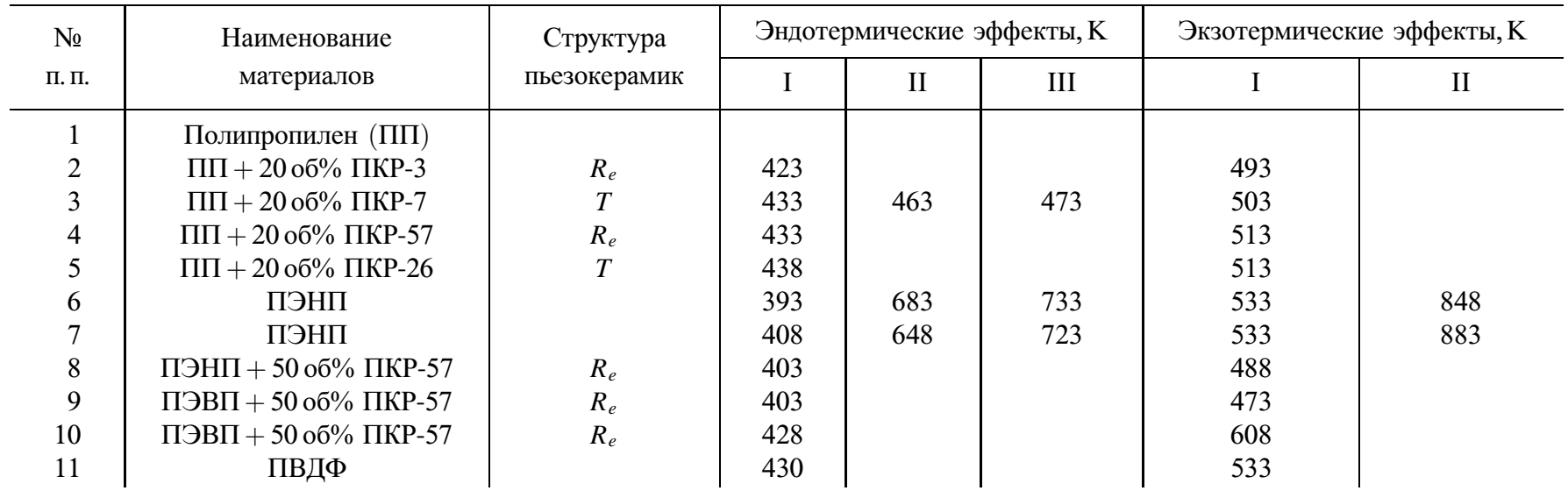

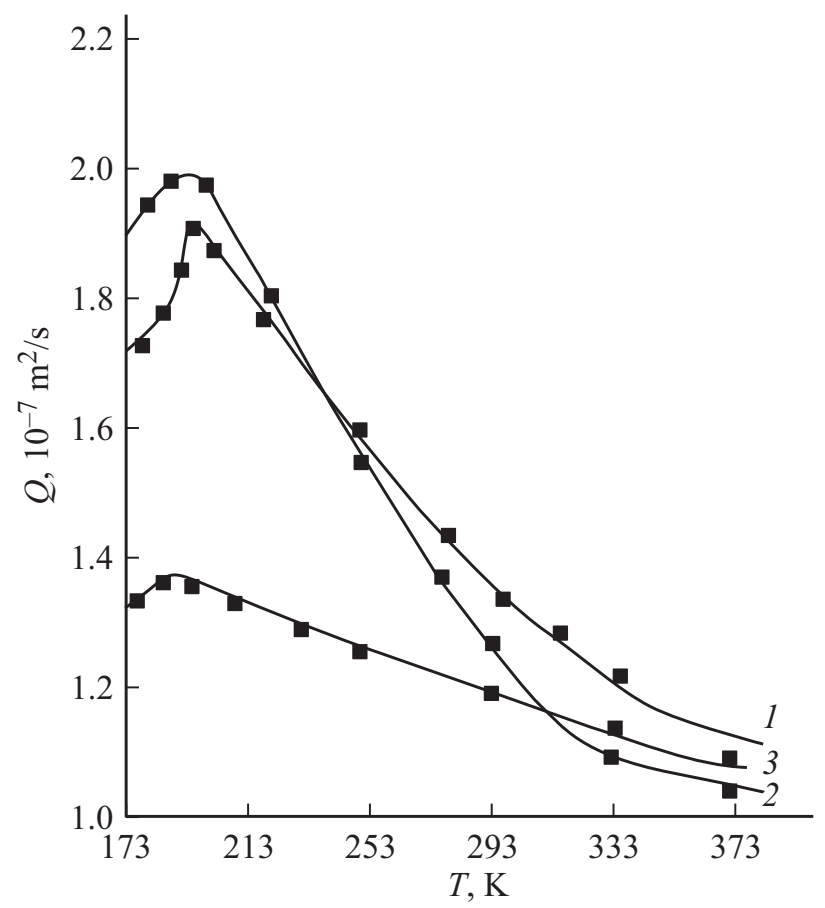

Рис. 3. Температурные зависимости коэффициента температуропроводности пьезокомпозитов: 1 - ПВДФ +20 об\% ПКР-3, 2 - ПВДФ + 20 об\% ПКР-7; 3 - ПВДФ + 20 об\% ПКР-57.

Результаты измеренных температурных зависимостей коэффицента температуропроводности $(Q)$ пьезокомпозитов на основе ПЭВП, ПВДФ и пьезокерамики $T$ и $R_{e}$ структур приведены на рис. 3. Наблюдается достаточно сильная температурная зависимость температуропроводности, нехарактерная для полимера или аморфных тел, что можно отнести за счет образования определенной структуры композитов. На наличие новых структурных изменений в композите указывают аномалии в области низких температур, наблюдающиеся в области 213-183 К. Отметим, также температурные зависимости коэффициента $Q$ композитов, которые зависят от структуры пьезокерамики. На рис. 4 приведены зависимости $Q$ от объемного содержания пьезокерамики для композитов на основе ПЭВП, ПВДФ и пьезокерамик $T$ и $R_{e}$ структур. Видно, что увеличение объемного содержания приводит к росту $Q$, при этом значение $Q$ заметно зависит от свойств полимерной матрицы и структуры пьезокерамики.

Межфазные явления исследовались методом дифференциально-термографиметрического анализа (ДТА). ДТА анализ показал, что у всех исследованных композитов наблюдается эндотермический эффект в области температур от 390 до $438 \mathrm{~K}$, а экзотермический эффект - в диапазоне $483-608$ К. Известно, что

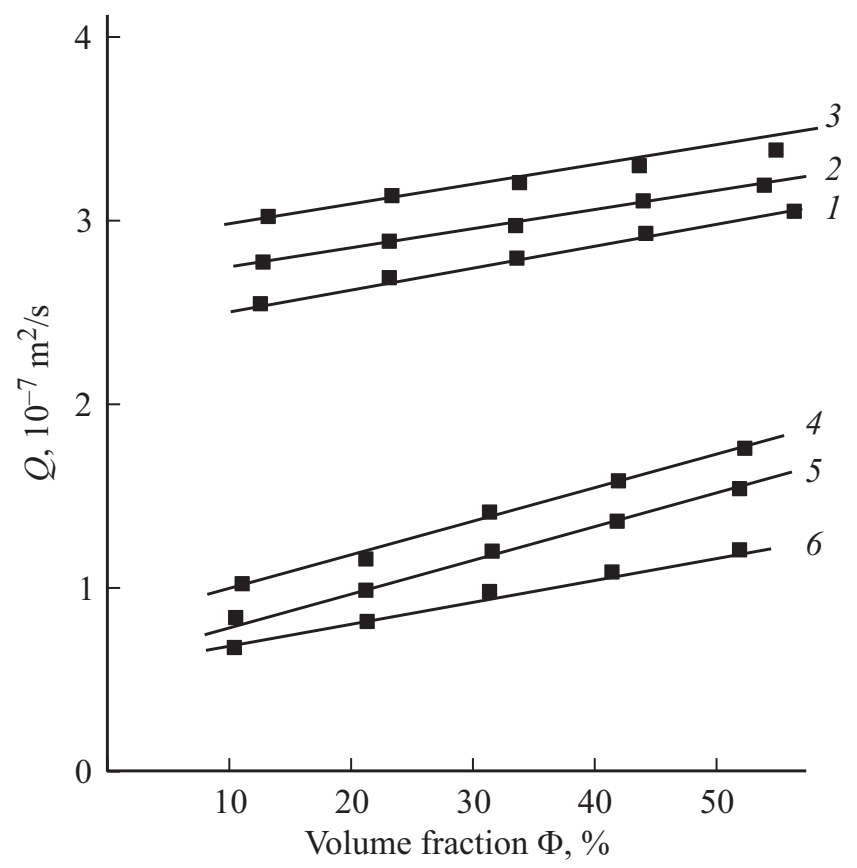

Рис. 4. Зависисимости $Q$ от объемного содержания пьезокерамики $(\phi)$ для композитов. 
эндотермический эффект в полимерах соответствует плавлению кристаллической фазы, а экзотермический эффект - деполимеризации полимерной цепи. В ДТА полиолефинов, например ПП, ПЭВП и ПЭНП, соответственно возникает эндотермический пик при 433, 408 и 393 К. При введении в ПП пьезокерамики ПКР ромбоэдрической и тетрагональной структур наблюдаются в ДТА новые эндотермические пики, причем температура возникновения их зависит от структуры и объемного содержания пьезокерамик (табл. 5), т. е. заметно растет взаимодействие на границе раздела фаз.

Изменение температуры возникновения эндотермического эффекта и появление нового эндотермического пика в ДТА композитов свидетельствуют о формировании нового кристаллического образования.

Можно предположить, что такое образование возникает на границе раздела фаз из-за взаимодействия полимерных цепей с поверхностью пьезочастиц, причем можно допустить, что пьезочастицы выполняют функцию центра кристаллизации. Из таблицы видно, что в случае пьезокерамики ПКР-3 температура возникновения первого эндотермического пика композитов на основе ПП заметно уменьшается. Для композитов на основе пьезокерамик тетрагональной структуры такие резкие изменения температуры эндотермического эффекта не наблюдаются, причем эта температура практически совпадает с температурой эндотермического эффекта исходной полимерной матрицы. Отметим, что для композитов на основе ПП с пьезокерамикой ПКР-3 второй эндотермический пик в ДТА наблюдается при температуре меньше, чем температура плавления кристаллической фазы ПП, а для композитов с пьезокерамиками $T$ структур, наоборот - выше температуры плавления кристаллической фазы ПП.

\section{4. Заключение}

Изучены релаксационные, термические процессы и межфазные явления в композитах и их влияние на макроскопические характеристики композитов полимерсегнетопьезокерамика различной структуры. Экспериментально установлено, что в композитах с пьезонаполнителем ромбоэдрической структуры $E_{a}, \Delta T$ и $S$ меньше, а $T_{M}$ и $\Delta T_{p}$ больше по сравнению с композитами, содержащими наполнители тетрагональной или смешанной структур. ДТА анализ показал, что у всех исследованных композитов наблюдается эндотермический эффект в области температур от 390 до $438 \mathrm{~K}$, а экзотермический эффект — в диапазоне $483-608 \mathrm{~K}$.

\section{Конфликт интересов}

Авторы заявляют, что у них нет конфликта интересов.

\section{Список литературы}

[1] М.К. Керимов, М.А. Курбанов, И.С. Султанахмедова, Ф.Н. Татардар, И.А. Фараджзаде, Х.С. Алиев, Ф.Ф. Яхъяев, У.В. Юсифова. ФТП, 44 (7), 934 (2010).

[2] G.A. Kontos, A.L. Soulintzis, P.K. Karahaliou, G.C. Psarras, S.N. Georga, C.A. Krontiras, M.N. Pisanias. Express Polymer Lett., 1 (12), 781 (2007).

[3] E.M. Godjaev, Sh.A. Zeynalov, S.S. Osmanova, E.A. Allakhyarov, O.A. Gumbatov. Fizika, XIII (5), 57 (2007).

[4] Г.А. Мамедов, А.Е. Панич, М.А. Курбанов, И.С. Султанахмедова, Ф.Н. Татардар, А.А. Мехтили, Ф.Ф. Яхъяев. ФТТ, 52 (6), 1067 (2010).

[5] M.K. Kerimov, M.A. Kurbanov, A.A. Bayramov, A.I. Mamedov. Matrix Active Micro and Nanocomposites Based on the Polymer, Semiconductive and Ferropiezoceramic Materials. Nanocomposites and Polymers with Analytical Methods/Book 3. Book ed. by John Cuppoletti (INTECH Open Access Publisher, 2011) p. 375.

[6] Б.Б. Колупаев, В.В. Клепко, Е.В. Лебедев. Акустичний вісник, 15 (2), 43 (2012).

[7] И.С. Рез, Ю.М. Поплавко. Диэлектрики. Основные свойства и применения в электронике (М., Радио и связь, 1989).

[8] Ю.А. Гороховатский, Г.А. Бордовский. Термоактиващионная токовая спектроскопия высокоомных полупроводников и диэлектриков (М., Наука, 1991).

[9] Е.Е. Фомичева, Д.Э. Темнов, М.Ф. Галиханов. Вестн. Казанского технол. ун-та, , № 10, 223 (2010).

[10] D. Hull, T.W. Clyne. An introduction to composite materials(Cambridge University Press, Cambridge, 1996).

[11] G.C. Psarras, E. Manolakaki, G.M. Tsangaris. Appl. Sci. Manufacturing, 33, 375 (2002).

[12] М.А. Курбанов, И.С. Рамазанова, З.А. Дадашев, У.В. Юсифова, Г.Х. Гусейнова, К.К. Азизова, И.А. Фараджзаде. ФТП, 52 (1), 68 (2018).

[13] G.M. Tsangaris, G.C. Psarras. J. Mater. Sci., 34, 2151 (1999).

[14] Е.Г. Фесенко, А.Я. Данцигер, О.Н. Разумовская. Новые пьезоэлектрические материалы (Ростов н/Д., РГУ, 1983).

[15] М.А. Курбанов, Ш.М. Ахадзаде, И.С. Рамазанова, 3.А. Дадашов, И.А. Фараджзаде. ФТП, 51 (7), 992 (2017).

[16] Y. Bai, Z.-Y. Cheng, V. Bharti, H.S. Xu, Q.M. Zhang. Appl. Phys. Lett., 76, 3804 (2000).

[17] H.J. Winkelhahn, S. Schrader, D. Neher, G. Wegner. Macromolecules, 28, 2882 (1995).

[18] Г.М. Магомедов. Релаксационные свойства полимерных композитных и нанокомпозитных материалов / Г.М. Магомедов, Х.Ш. Яхьяева (М., Перо, 2015).

[19] Н.М. Ливанова. ВМС, А, 48 (8), 1424 (2006).

[20] M.A. Kurbanov, A.A. Bayramov, N.A. Safarov, F.N. Tatardar, İ.S. Sultanaxmedova. Scientific Israel Technol. Adv., 14 (1), 1 (2012).

[21] М.А. Курбанов. Автореф. докт. дис. (Баку, 1985).

Редактор А.Н. Смирнов 


\title{
Relaxation, thermal and interphase \\ effects in composites of polymer-segnetopiezokeramics of various structure
}

M.A. Kurbanov ${ }^{1}$, I.S. Ramazanova ${ }^{1}$, Z.A. Dadashov' ${ }^{1}$, F.I. Mamedov ${ }^{3}$, G.Kh. Huseynova ${ }^{1}$, U.V. Yusifova ${ }^{1}$, F.N. Tatardar ${ }^{1,2}$, I.A. Faraczade ${ }^{4}$

${ }^{1}$ Institute of Physics, National Academy of Sciences of Azerbaijan, Az-1143 Baku, Azerbaijan

${ }^{2}$ Khazar University, Az-1096 Baku, Azerbaijan

${ }^{3}$ Academy under the Ministry of Emergency Situations, Az-1089 Baku, Azerbaijan

${ }^{4}$ Institute of Radiation Problems of the National Academy of Sciences of Azerbaijan, Az-1143 Baku, Azerbaijan

\begin{abstract}
Relaxation, thermal processes and interphase phenomena in composites based on the piezoelectric phase and the polymer matrix have been studied. It is shown that the value of the charge stabilized at the interface of the composite phases during its electrothermopolarization is mainly determined by the structure of the polymer matrix and the piezoelectric phase. The results obtained make it possible to identify the main causes that affect the piezoelectric properties of the heterogeneous polymer-ferroelectric ceramic system. As the organic phase, polyolefins and fluorinecontaining polar polymers were used, and as an inorganic phase, ferroeoceramic, rhombohedral, tetragonal and mixed structures. Relaxation processes and interphase phenomena are studied using the differential scanning calorimeter, and the charge state by recording the thermally stimulated depolarization current. The stability of the charge state was determined by the electret potential difference of the composites. The study of molecular relaxation was also carried out by the dielectric method. It was established that composites in which the interfacial interaction manifests itself more strongly have high piezoelectric properties.
\end{abstract}

